\title{
The association between diabetes mellitus, glucose, and chronic musculoskeletal complaints. Results from the Nord-Trøndelag Health Study
}

\author{
Ole M Hoff' ${ }^{1}$, Kristian Midthjell ${ }^{2}$, John-Anker Zwart1 ${ }^{13,4}$ and Knut Hagen*1,3
}

\begin{abstract}
Address: ${ }^{1}$ Department of Neuroscience, Faculty of Medicine, Norwegian University of Science and Technology, Trondheim, Norway, ${ }^{2} \mathrm{HUNT}$ research centre, Department of Public Health, Faculty of Medicine, Norwegian University of Science and Technology, Trondheim, Norway, ${ }^{3}$ Norwegian National Headache Centre, Section of Neurology, St. Olav's Hospital, Trondheim, Norway and ${ }^{4}$ Department of Neurology, Ullevål University Hospital, and Faculty of Medicine, University of Oslo, Oslo, Norway

Email: Ole M Hoff - olemarho@stud.ntnu.no; Kristian Midthjell - kristian.midthjell@ntnu.no; John-Anker Zwart - j.a.zwart@medisin.uio.no; Knut Hagen* - knut.hagen@ntnu.no

* Corresponding author
\end{abstract}

Published: 2 December 2008

BMC Musculoskeletal Disorders 2008, 9:160 doi:10.1/86/1471-2474-9-160

This article is available from: http://www.biomedcentral.com/I47/-2474/9//60

(C) 2008 Hoff et al; licensee BioMed Central Ltd.

This is an Open Access article distributed under the terms of the Creative Commons Attribution License (http://creativecommons.org/licenses/by/2.0), which permits unrestricted use, distribution, and reproduction in any medium, provided the original work is properly cited.
Received: 27 June 2008

Accepted: 2 December 2008

\begin{abstract}
Background: The relationship between diabetes mellitus (DM) and chronic musculoskeletal complaints (MSCs) is unclear. The aim of this study was to investigate the association between DM, non-fasting glucose and chronic MSCs defined as pain and/or stiffness $\geq 3$ months during the past year in the general adult population.

Methods: The results were based on cross-sectional data from 64,785 men and women (aged $\geq$ 20 years) who participated in the Nord-Trøndelag Health Survey, which included 1,940 individuals with known DM. Associations were assessed using multiple logistic regression, estimating prevalence odds ratio (OR) with $95 \%$ confidence intervals $(\mathrm{Cls})$.

Results: High non-fasting glucose was associated with a lower prevalence of chronic MSCs compared to a low glucose level. DM was associated with higher prevalence of chronic MSCs, in particular chronic widespread MSCs. In the multivariate analysis, adjusting for glucose level, BMI, age, gender and physical activity, chronic widespread MSCs was I.6 times more likely $(\mathrm{OR}=1.6$, $95 \% \mathrm{Cl}$ I.2-2.2) among individuals $<60$ years of age with DM than among those without DM. The association between chronic widespread MSCs and DM was most evident among the group of individuals aged $<60$ years with either type 2 DM or unclassified DM (OR = I.8, 95\% Cl I.3-2.5).
\end{abstract}

Conclusion: In this cross-sectional study a high non-fasting glucose was associated with lower prevalence of chronic MSCs. Among individuals with known DM chronic widespread MSCs were more likely.

\section{Background}

Musculoskeletal complaints (MSCs) are among the major health problems worldwide and the most frequent cause of long-term sickness leave in Norway [1,2]. Increased mortality has been reported among individuals with chronic widespread MSCs [3], which further emphasizes that this group of patients may constitute an important public health problem. 
In Nord-Trøndelag County in Norway $45 \%$ of the adult population reported chronic MSCs during the last year [4]. The prevalence of known diabetes mellitus (DM) was 3\% [5]. Despite that both disorders are relatively common, few studies have focused on the relationship between chronic MSCs and diabetes mellitus (DM). DM has been associated with increased fracture risk [6] and rotator cuff tendinitis [7]. Some studies have reported reduced pain thresholds in individuals with hyperglycemia $[8,9]$, but the relationship between DM and chronic MSCs remains unclear.

To clarify the potential association between DM and chronic MSCs a cross-sectional study is a time effective first-step which also may provide clues to the pathophysiology of chronic MSCs. The main purpose of this large population-based cross-sectional study was to evaluate the association between DM, non-fasting glucose and chronic MSCs.

\section{Methods}

Between 1995 and 1997, all inhabitants aged 20 years and above were invited to participate in the Nord-Trøndelag Health Survey (the HUNT study). Details of this comprehensive health study are described elsewhere [10]. In short, two questionnaires including more than 200 health-related questions were administered to the participants. The first questionnaire (Q1) was sent along with the invitation, and delivered when attending the health examination during which non-fasting blood samples were drawn. All participants received a second questionnaire (Q2) which was returned by postal mail. Out of the 92,936 invited individuals, $65,081(70.0 \%)$ answered the first question about DM, whereas 64,785 (69.7\%) responded to the first question about MSCs.

\section{Musculoskeletal complaints}

Both Q1 and Q2 included questions about musculoskeletal symptoms adopted from the Standardized Nordic Questionnaire, which has previously been evaluated and found to give reliable estimates for low back and upper limb and neck discomfort, in particular for symptoms during the past year [11-13]. In Q1 participants were asked whether they had suffered pain or stiffness in muscles and joints lasting for at least 3 months during the last year, whereas in Q2, they were asked to indicate the number of days during the last month of such complaints. In both questionnaires, those participants who responded "yes" were then asked to tick off one or several of the following nine areas of the body; neck, shoulders, elbows, wrist/hands, upper back, low back, hips, knees, and/or ankles/feet.

In the present study, individuals with chronic MSCs (pain and/or stiffness $\geq 3$ months during the past year) were subdivided into chronic widespread MSCs and chronic non-widespread MSCs. "Chronic widespread MSCs" were defined as pain and/or stiffness $\geq 3$ month during the past year and $\geq 15$ days with symptoms during the last month from all of the following regions: axial skeletal pain (pain in the neck, chest/abdomen, upper back, or lower back), pain above the waist (neck, shoulders, elbows, wrist/ hands, chest/abdomen, or upper back) and below the waist (lower back, hips, knees, or ankles/feet). Individuals with chronic MSCs not fulfilling the criteria for chronic widespread MSCs were defined as having chronic nonwidespread MSCs (mutually exclusive).

\section{Diabetes mellitus}

Non-fasting glucose was drawn from more than $99 \%$ of the participants who attended the clinical examination. Fasting glucose, glycosylated hemoglobin (HbA1c), Cpeptide and anti-glutamic acid decarboxylase (anti-GAD) was drawn from $74 \%$ of the participants with a positive answer to the question "Do you have or have you ever had diabetes?" in Q1 (known DM). Known DM was reported in a total of $1,940(3 \%)$ out of the 64,785 participants who responded to the first question about MSCs. A total of 216 persons with no previous known DM had non-fasting glucose $\geq 11.1$. Although a considerable proportion of these probably had previously undiscovered DM, these were included as a separate group in our analyses.

Patients starting insulin treatment within 6 months of diagnosis were classified as having type $1 \mathrm{DM}$ (classic type $1)$, if, in addition, they were anti-GAD positive $(\geq 0.08)$ or had C-peptide levels $<150 \mathrm{pmol} / \mathrm{l}(\mathrm{n}=122)$. Type 2 diabetic subjects were anti-GAD negative $(<0.08)$ and had not received insulin treatment within one year of diagnosis $(\mathrm{n}=1120)$. LADA was defined by anti-GAD positivity and no insulin treatment within 12 months after diagnosis $(\mathrm{n}=127)$. For gestational diabetes mellitus (GMD) the criteria were anti-GAD negative and no insulin treatment, and/or other information about diabetes during pregnancy $(\mathrm{n}=12)$. The criteria for MODY were anti-GAD negative and debut $<25$ years and diabetes in relatives and no insulin treatment started within 12 months after debut (n $=8$ ). Only 20 persons fulfilled the criteria for MODY or GDM, and these were therefore merged together with the unclassified group, consisting of patients with incomplete information on insulin treatment and results of C-peptide and anti-GAD.

\section{Statistical analysis}

Differences between continuous variables were tested with analyses of variance (one-way ANOVA) and between proportions by chi-squared test. In the multivariate analyses, using logistic regression, we estimated the prevalence odds ratio (OR) with 95\% confidence interval (CI) for the association between chronic MSCs and DM. We adjusted 
for age, body mass index (BMI), gender and physical activity as confounders. Other potential confounding factors like education, occupation, smoking, previous myocardial infarction, alcohol consumption, and mean systolic blood pressure were also evaluated, but were excluded from the final analyses because they changed the OR by less than $5 \%$. Serum glucose, $\mathrm{HbA}_{1 c^{\prime}}$ and duration of $\mathrm{DM}$ were categorized into quartiles based on individual values, but in separate analyses also treated as a continuous variable. When appropriate, serum glucose was also treated as a single ordinal variable (categories 1 to 4 based on quartiles) and was incorporated in a two sided test for trend to evaluate the probability of a linear relationship between glucose categories and prevalence of MSCs. We also investigated potential interaction between age and diabetes status by including the product of the two variables into the logistic regression analyses. The interaction coefficient was tested using Wald $\chi^{2}$ statistics. Data analyses were performed with the Statistical Package for the Social Sciences, version 15.0 (SPSS, Chicago, Illinois, USA)

The study was approved by the Regional Committee for Ethics in Medical Research, and the HUNT Study is also approved by the Norwegian Data Inspectorate.

\section{Results}

Among the 64,785 participants, 30,157 (46.5\%) reported chronic MSCs, whereof 3,240 (5.0\%) had chronic widespread MSCs, and the remaining 26,917 (41.5\%) chronic non-widespread MSCs. The prevalence of chronic MSCs increased with age with a peak in the age group 60-64 years $(59.7 \%)$, and were higher for women than men in all age groups (overall $50.1 \%$ versus $42.6 \%$, $\mathrm{p}<0.001$ ). The prevalence of chronic MSCs also increased with BMI with a peak among obese with $\mathrm{BMI} \geq 30 \mathrm{~kg} / \mathrm{m}^{2}(54.6 \%)$, and were higher among the physically inactive than active individuals $(55.4 \%$ versus $44.9, \mathrm{p}<0.001)$.

Educational level, level of physical activity, and proportion of smokers were lower among individuals with DM compared to those without DM, whereas, age, BMI, mean systolic BP, and prevalence of alcohol abstainers and myocardial infarction were significantly higher $(\mathrm{p}<$ 0.001 ) Table 1). The proportion of women did not differ significantly between the groups with or without DM ( $\mathrm{p}=$ $0.20)$. Among individuals with $D M$, those with type $1 \mathrm{DM}$ was youngest and most likely to be men (Table 1).

In the multivariate analyses, adjusting for age, BMI, gender and level of physical activity as confounding factors, prevalence of chronic MSCs was higher among patients with $\mathrm{DM}$ than among individuals without $(\mathrm{OR}=1.2,95 \%$ CI 1.1-1.3, Table 2). This association was most evident among individuals with chronic widespread MSCs (OR = $1.3,95 \%$ CI 1.1-1.6). The difference in unadjusted prevalence of chronic widespread MSCs between individuals with or without DM was most prominent in those below 60 years of age (Fig. 1). Although no significant interaction was found between age and diabetes status in the multivariate analyses $(\mathrm{p}=0.16)$, chronic widespread MSCs was 1.5 times more likely $(\mathrm{OR}=1.5,95 \%$ CI 1.1 2.1) among subjects with DM than among those without in a separate analysis for individuals $<60$ years. Among those 60 years and older, the corresponding OR was 1.1 $(0.8-1.5)$.

Among the group of 216 individuals with non-fasting glucose $\geq 11.1$ (but not known DM), chronic MSCs was less likely $(\mathrm{OR}=0.7,95 \% \mathrm{CI} 0.5-0.9)$ than among those with no DM (Table 2). Furthermore, there was a linear trend ( $p$ $<0.001$ ) of decreasing prevalence of chronic MSCs with

Table I: Background data on persons without and with known diabetes mellitus (DM) (type I, type 2, type 2, LADA, and other types/ unclassified)

\begin{tabular}{|c|c|c|c|c|c|c|c|}
\hline Variables & No DM & All DM types & $\begin{array}{l}\text { Classical } \\
\text { Type I DM }\end{array}$ & Type 2 DM & LADA & $\begin{array}{c}\text { Other types/unclassified } \\
\text { DM }\end{array}$ & $\begin{array}{c}\text { Not DM, but glucose } \geq \\
\text { II.I }\end{array}$ \\
\hline$n$ & 62,626 & 1940 & 122 & 1120 & 127 & 571 & 216 \\
\hline Gender, female (\%) & 53.2 & 51.7 & 41.0 & 50.5 & 46.5 & 57.4 & 37.5 \\
\hline Mean age & 48.4 & 64.4 & 47.5 & 67.1 & 67.4 & 63.1 & 61.6 \\
\hline $\begin{array}{l}\text { Years of education } \geq 13 \\
\text { (\%) }\end{array}$ & 19.3 & 9.1 & 19.7 & 6.5 & 11.0 & 10.3 & 12.0 \\
\hline Mean BMI & 26.3 & 29.0 & 26.1 & 29.6 & 28.5 & 28.6 & 29.5 \\
\hline Current smoking (\%) & 28.9 & 17.5 & 24.6 & 15.4 & 9.4 & 21.9 & 26.9 \\
\hline High physical activity* (\%) & 16.1 & 7.8 & 13.9 & 7.2 & 11.0 & 6.8 & 4.6 \\
\hline Alcohol abstainers (\%) & 12.2 & 30.8 & 13.7 & 32.0 & 36.1 & 31.0 & 17.2 \\
\hline $\begin{array}{l}\text { Previous myocardial } \\
\text { infarction }\end{array}$ & 3.0 & 12.7 & 5.7 & 13.5 & 12.0 & 12.9 & 5.6 \\
\hline $\begin{array}{l}\text { Mean systolic blood } \\
\text { pressure }\end{array}$ & 137 & 154 & 140 & 156 & 154 & 153 & 156 \\
\hline
\end{tabular}

\footnotetext{
* High physical activity level $=\geq 3$ hours/week with hard physical activity
} 


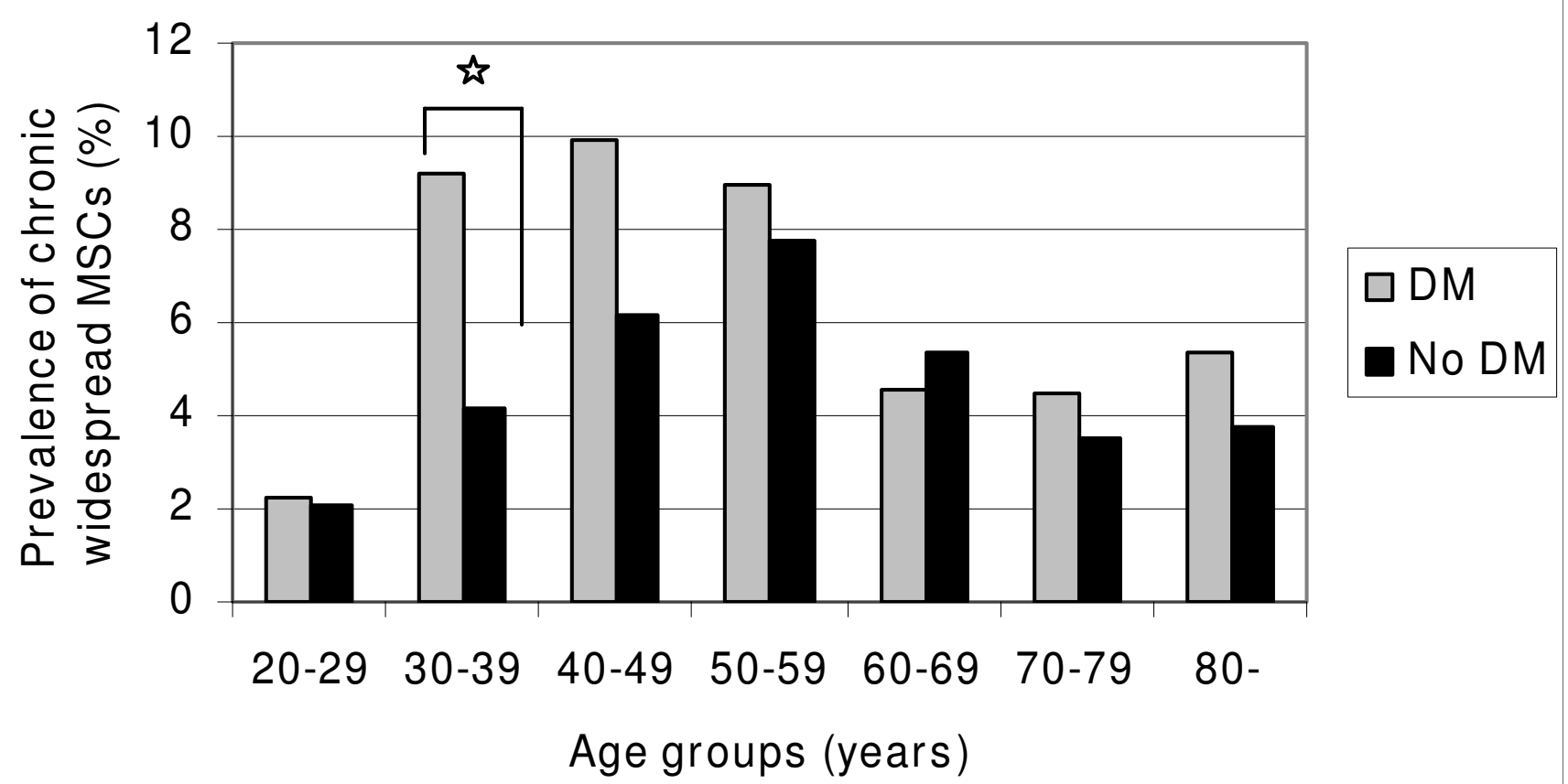

Figure I

Prevalence (\%) of chronic widespread MSCs by age group. * $p<0.05$.

increasing non-fasting glucose categories, also evident when glucose was treated as a continuous variable (Table 2 ). The prevalence OR of chronic widespread MSCs was 0.8 (95\% CI 0.7-0.9) for individuals with glucose $\geq 5.9$ $\mathrm{mmol} / \mathrm{l}$ compared to those with glucose $\leq 4.7 \mathrm{mmol} / \mathrm{l}$ (Table 2). Thus, when adjusting for non-fasting serum glucose, chronic widespread MSCs was 1.6 times more likely $(\mathrm{OR}=1.6,95 \%$ CI 1.2-2.2) among subjects $<60$ years of age with DM than among those without.

Chronic widespread MSCs were more likely among individuals with type $2 \mathrm{DM}(\mathrm{OR}=1.3,95 \% \mathrm{CI} 1.0-1.7)$ and unclassified DM (OR = 1.6, 95\% CI 1.1-2.3) than among those without DM (Table 2 ). When adjusting for non-fasting glucose, the corresponding ORs increased to 1.4 (95\% CI 1.1-1.8) and 1.7 (95\% CI 1.2-2.5) respectively. Among women, the strongest association was found with unclassified DM (OR = 2.1, 95\% CI 1.3-3.3), whereas for type 2 DM among men (OR = 1.5, 95\% CI 1.0-2.2). When merging individuals with type 2 DM and unclassified DM, chronic widespread MSCs were 1.5 times more likely (OR $=1.5,95 \%$ CI $1.2-1.9$ ) for this combined group compared to those without DM. The corresponding OR for those $<60$ years was $1.8(1.3-2.5)$. No significant association was found between chronic MSCs and type 1 DM or latent autoimmune diabetes of the adult (LADA) (Table 2).
Among the group of 1940 individuals with DM, no clear association was found between chronic MSCs and neither non-fasting serum glucose, $\mathrm{HbA}_{1 \mathrm{c}^{\prime}}$ nor duration of $\mathrm{DM}$ when treated as a single ordinal variable (Table 3 ). However, when $\mathrm{HbA}_{1 \mathrm{c}}$ was treated as a continuous variable, there was a linear trend ( $p<0.036, \beta=-, 055)$ of decreasing prevalence of chronic non-widespread MSCs with increasing $\mathrm{HbA}_{1 \mathrm{c}}$.

\section{Discussion and conclusion}

In this large-scale population-based cross-sectional study a high non-fasting glucose was associated with a lower prevalence of chronic MSCs, whereas individuals with DM were more likely to report chronic widespread MSCs than those without DM.

The strength of this study was the large and unselected population. To the best of our knowledge, this is the first large-scale population-based study evaluating the influence of chronic MSCs on individuals with DM whose classification is based on results of blood samples with antiGAD and C-peptide in addition to questionnaire-based data. Although the participation rate of $70 \%$ was high, one may question to what degree the results can be generalized. Because questions about musculoskeletal pain were only a few out of more than 200 health-related questions, there is probably no selection bias regarding 
Table 2: Prevalence OR\# of musculoskeletal complaints (MSCs) related to DM and non-fasting glucose levels

\begin{tabular}{|c|c|c|c|c|c|c|c|}
\hline \multirow[t]{2}{*}{ Variables } & \multirow{2}{*}{$\begin{array}{l}\text { Total } \\
64,785\end{array}$} & \multicolumn{2}{|c|}{ Chronic MSCs } & \multicolumn{2}{|c|}{ Chronic widespread MSCs MSCs } & \multicolumn{2}{|c|}{ Chronic non-widespread MSCs } \\
\hline & & $\%$ & $\mathrm{OR}(\mathrm{Cl})$ & $\%$ & OR $(\mathrm{Cl})$ & $\%$ & OR (Cl) \\
\hline \multicolumn{8}{|l|}{ DM } \\
\hline No & 62,629 & 46.2 & 1.0 (reference) & 5.0 & I.0 (reference) & 41.3 & I.0 (reference) \\
\hline Yes & 1,940 & 56.9 & $1.2(1.1-1.3)$ & 5.9 & $1.3(1.1-1.6)$ & 51.0 & I.I (I.0-1.3) \\
\hline No, but glucose $\geq I I . I$ & 216 & 45.4 & $0.7(0.5-0.9)$ & 5.1 & $0.8(0.4-1.5)$ & 40.3 & $0.7(0.5-0.9)$ \\
\hline \multicolumn{8}{|l|}{ DM } \\
\hline No & 62,629 & 42.2 & 1.0 (reference) & 5.0 & I.0 (reference) & 41.3 & I.0 (reference) \\
\hline Type I & 122 & 45.9 & $1.0(0.7-1.5)$ & 3.3 & $0.7(0.2-1.9)$ & 42.6 & I.I (0.7-I.6) \\
\hline Type 2 & 1,120 & 57.7 & I.I (I.0-1.3) & 6.1 & $1.3(1.0-1.7)$ & 51.6 & $1.1(1.0-1.3)$ \\
\hline LADA & 127 & 56.7 & I.I (0.8-1.6) & 5.5 & $1.2(0.5-2.6)$ & 51.2 & $1.2(0.8-1.7)$ \\
\hline Unclassified & 571 & 57.8 & $1.2(1.0-1.5)$ & 6.3 & $1.6(1.1-2.3)$ & 51.5 & $1.2(1.0-1.4)$ \\
\hline No, but glucose $\geq I I . I$ & 216 & 45.4 & $0.7(0.5-0.9)$ & 5.1 & $0.8(0.4-1.5)$ & 40.3 & $0.7(0.5-0.9)$ \\
\hline \multicolumn{8}{|l|}{ Serum glucose } \\
\hline$\leq 4.7 \mathrm{mmol} / \mathrm{l}$ & 16,198 & 43.2 & 1.0 (reference) & 4.8 & I.0 (reference) & 38.3 & I.0 (reference) \\
\hline $4.8-5.2 \mathrm{mmol} / \mathrm{l}$ & $|9,15|$ & 46.7 & $1.0(0.9-1.0)$ & 5.2 & $1.0(0.9-1.1)$ & 41.4 & $1.0(0.9-1.0)$ \\
\hline $5.3-5.8 \mathrm{mmol} / /$ & 14,737 & 47.9 & $0.9(0.9-1.0)$ & 5.1 & $0.9(0.8-1.0)$ & 42.8 & $0.9(0.9-1.0)$ \\
\hline$\geq 5.9 \mathrm{mmol} / \mathrm{l}$ & 14,316 & 49.1 & $0.9(0.8-0.9)$ & 5.0 & $0.8(0.7-0.9)$ & 44.2 & $0.9(0.8-0.9)$ \\
\hline Missing & 383 & 36.6 & $0.6(0.5-0.8)$ & 0.8 & $0.1(0.0-0.4)$ & 35.8 & $0.6(0.5-0.8)$ \\
\hline P-trend value $\$$ & & & $<0.001$ & & $<0.001$ & & $<0.001$ \\
\hline $\mathrm{P}$ trend value $\$(\beta)$ & & & $<0.001(-, 022)$ & & $0.045(-, 026)$ & & $<0.00 \mathrm{I}(-, 02 \mathrm{I})$ \\
\hline
\end{tabular}

\# Adjusted for age, gender, body mass index, and level of physical activity

$\$$ Serum glucose treated as a single ordinal variable (categories I to 4 based on quartiles)

$\S$ Serum glucose treated as a continuous variable ( $\beta$ value given in brackets)

Table 3: Prevalence OR\# of musculoskeletal complaints (MSCs) related to fasting serum glucose, HbAlc and duration of the disease in patients with DM

\begin{tabular}{|c|c|c|c|c|c|c|c|}
\hline \multirow[t]{2}{*}{ Variables } & \multirow{2}{*}{$\begin{array}{l}\text { Total } \\
1940\end{array}$} & \multicolumn{2}{|c|}{ Chronic MSCs } & \multicolumn{2}{|c|}{ Chronic widespread MSCs } & \multicolumn{2}{|c|}{ Chronic non-widespread MSCs } \\
\hline & & $\%$ & OR $(\mathrm{Cl})$ & $\%$ & $\mathrm{OR}(\mathrm{Cl})$ & $\%$ & OR $(\mathrm{Cl})$ \\
\hline \multicolumn{8}{|l|}{ Serum glucose } \\
\hline$\leq 6.3 \mathrm{mmol} / \mathrm{l}$ & 482 & 59.3 & I.0 (reference) & 6.4 & 1.0 (reference) & 52.9 & I.0 (reference) \\
\hline $6.4-8.7 \mathrm{mmol} / \mathrm{l}$ & 487 & 55.2 & $0.8(0.6-I . I)$ & 5.1 & $0.7(0.4-1.2)$ & 50.1 & $0.8(0.6-1.1)$ \\
\hline $8.8-12.1 \mathrm{mmol} / \mathrm{l}$ & 472 & 54.9 & $0.8(0.6-1.1)$ & 6.1 & $0.8(0.5-1.4)$ & 48.7 & $0.8(0.6-1.1)$ \\
\hline$\geq 12.2 \mathrm{mmol} / \mathrm{l}$ & 469 & 57.4 & $1.0(0.7-1.3)$ & 6.4 & $1.0(0.6-1.8)$ & 51.0 & $1.0(0.7-1.3)$ \\
\hline Missing & 30 & 70.0 & $1.2(0.5-3.0)$ & 0.0 & - & 70.0 & $1.5(0.6-3.6)$ \\
\hline \multicolumn{8}{|l|}{ HbAlc } \\
\hline$\leq 6.8 \mathrm{mmol} / \mathrm{l}$ & 509 & 57.2 & 1.0 (reference) & 6.7 & 1.0 (reference) & 50.5 & I.0 (reference) \\
\hline $6.9-7.8 \mathrm{mmol} / \mathrm{l}$ & 422 & 59.2 & I.I (0.9-I.5) & 5.0 & $0.8(0.4-1.5)$ & 54.3 & $1.2(0.9-1.5)$ \\
\hline $7.9-9.2 \mathrm{mmol} / \mathrm{l}$ & 481 & 55.7 & I.0 (0.7-I.2) & 5.2 & $0.8(0.5-1.4)$ & 50.5 & $1.0(0.8-1.3)$ \\
\hline$\geq 9.3 \mathrm{mmol} / \mathrm{l}$ & 426 & 53.8 & $0.9(0.7-1.2)$ & 7.0 & $1.0(0.6-1.7)$ & 46.7 & $0.9(0.7-1.2)$ \\
\hline Missing & 102 & 64.7 & $1.4(0.9-2.1)$ & 4.9 & $0.8(0.3-2.4)$ & 59.8 & I.4 (0.9-2.3) \\
\hline \multicolumn{8}{|l|}{ Duration of DM } \\
\hline$\leq 2$ years & 502 & 56.2 & 1.0 (reference) & 6.4 & 1.0 (reference) & 49.8 & I.0 (reference) \\
\hline $3-6$ years & 360 & 56.4 & $1.0(0.8-1.4)$ & 4.7 & $0.8(0.4-1.4)$ & 51.7 & I.I (0.8-I.4) \\
\hline $7-13$ years & 403 & 57.1 & I.I (0.8-I.4) & 6.0 & I.I (0.6-2.I) & 51.1 & I.I (0.8-I.5) \\
\hline$\geq 14$ years & 406 & 59.1 & $1.2(0.9-1.6)$ & 6.9 & $1.6(0.9-2.8)$ & 52.2 & $1.2(0.9-1.6)$ \\
\hline Missing & 269 & 55.4 & $1.0(0.7-1.3)$ & 5.2 & $1.0(0.5-2.1)$ & 50.2 & $\mathrm{I} .0(0.7-1.3)$ \\
\hline
\end{tabular}

\# Adjusted for age, gender, body mass index, and level of physical activity

$\$$ Serum glucose treated as a single ordinal variable (categories I to 4 based on quartiles)

$\S$ Serum glucose treated as a continuous variable ( $\beta$ value given in brackets) 
chronic MSCs. However, the possibility of a recruitment bias regarding DM should not be ignored. Non-responders were more frequent among young persons and among very old [10]. Particular selection by health status was more likely among the elderly [14]. The non-response problems related to the HUNT study have been thoroughly discussed elsewhere [14].

The participants were not asked to distinguish between pain in the left and right side of the body, and therefore we could not use the American College of Rheumatology (ACR) definition of chronic widespread pain. The group of individuals with chronic widespread MSCs was probably heterogeneous, but it may be of some relevance that a self-reported diagnosis of fibromyalgia was more than 5 times more common among individuals with chronic widespread MSCs than in those without. In the present study DM was associated with an increased prevalence of chronic widespread MSCs. A high prevalence of fibromyalgia has been reported among 100 patients with DM, both in type 1 and type 2 , and a positive correlation between higher levels of HbA1c and more tender points [15]. Similarly, fibromyalgia was more likely among women with type 2 DM compared to controls [16], and the majority of a group of Italian patients with DM reported chronic musculoskeletal pain [17]. In the present study we found the strongest association between chronic widespread MSCs and the combined group of individuals with type 2 DM or unclassified DM. The positive relationship between type $2 \mathrm{DM}$ and chronic widespread MSCs found in the present study raises the question whether type $2 \mathrm{DM}$ may in some ways worsen chronic widespread MSCs, or vice versa. The causality issue cannot be properly addressed in a cross-sectional study. Age, overweight, and physical inactivity are strong risk factors for type DM [18], but we adjusted for all these factors in the analysis, and potential confounding was also evaluated for other lifestyle factors such as smoking and alcohol use. However, one can not rule out the possibility that there may be other unmeasured life-style factors or other factors incompletely registered that could influence our findings. For example, among those with known DM, anxiety and other psychological factors may influence their response to the questions about MSCs. One may also speculate that attempts to keep the glucose level low may influence the occurrence of chronic MSCs. DM affects vascular reactivity $[19,20]$, and induces diabetic neuropathy [21], but because no association was found between chronic MSCs and type 1 DM or LADA, other causes than vascular changes may probably explain our main findings.

To the best of our knowledge, this is the first study evaluating the influence of non-fasting glucose on chronic MSCs in the general population. A subgroup of 216 individuals had non-fasting glucose $\geq 11.1$, but they were not aware of DM at the time of the blood sampling. Therefore, anxiety for DM probably did not influence their response to the questions about MSCs. We found that hyperglycemia was associated with lower prevalence of chronic MSCs. Thus, our findings did not indicate that hyperglycemia per se increased the risk of chronic pain, at least in a short time perspective. Previously, several studies have reported reduced pain thresholds in hyperglycemia, but these studies have mainly been restricted to patients with known DM or diabetic animals [9,22-24]. In the present study no consistent association was found between nonfasting glucose, $\mathrm{HbA}_{1 c^{\prime}}$ and prevalence of chronic MSCs among those with known DM. Thus, our results did not indicate that poor control of DM increases the prevalence of chronic MSCs as compared to good control defined as low $\mathrm{HbA}_{1 \mathrm{c}}$ or low non-fasting glucose level.

In the present study high non-fasting glucose was associated with a lower prevalence of chronic MSCs, which may provide clues to the pathophysiology of chronic MSCs. High glucose levels or poor control of DM can of course not be recommended in a public health perspective.

\section{Competing interests}

The authors declare that they have no competing interests.

\section{Authors' contributions}

$\mathrm{OMH}$, and $\mathrm{KH}$ conceived of the study and performed the statistical analysis. OMH, KM, JAZ and $\mathrm{KH}$ all participated in the design and drafted the manuscript. KM planned and was responsible for collection of data on diabetes. All authors read and approved the final manuscript.

\section{Acknowledgements}

The Nord-Trøndelag Health Study (The HUNT study) is a collaboration between the HUNT Research Centre, Faculty of Medicine, the Norwegian University of Science and Technology (NTNU); Norwegian Institute of Public Health; and the Nord-Trøndelag County Council.

\section{References}

I. WHO Scientific Group on the Burden of musculoskeletal conditions at the start of the new millenium: The burden of musculoskeletal conditions at the start of the new millennium. In World Health Organ Tech Rep Ser Volume 919. Geneva, Switzerland: World Health Organization; 2003:i-x, I-218, back cover.

2. Statistics of sick leave in Norway in 2007 [http://www.nav.no]

3. Andersson $\mathrm{HI}$ : The course of non-malignant chronic pain: a I2year follow-up of a cohort from the general population. Eur J Pain 2004, 8:47-53.

4. Svebak S, Hagen K, Zwart J-A: Prevalence of chronic musculoskeletal pain in an adult Norwegian county population. Relation with age and gender. The HUNT study. J Musk Pain 2006, 14:2I-28.

5. Stene LC, Midthjell K, Jenum AK, Skeie S, Birkeland KI, Lund E, Joner G, Tell GS, Schirmer H: Prevalence of diabetes mellitus in Norway. Tidsskr Nor Lægeforen 2004, I 24: I5 I I-I5I4.

6. Vestergaard P: Discrepancies in bone mineral density and fracture risk in patients with type $I$ and type 2 diabetes - a metaanalysis. Osteoporos Int 2007, 18:427-444.

7. Miranda H, Viikari-Juntura E, Heistaro S, Heliövaara M, Riihimäki H: A population study on differences in the determinants of a spe- 
cific shoulder disorder versus nonspecific shoulder pain without clinical findings. Am J Epidemiol 2005, 161:847-855.

8. Morley GK, Mooradian AD, Levine AS, Morley JE: Mechanism of pain in diabetic peripheral neuropathy. Effect of glucose on pain perception in humans. Am J Med 1984, 77:79-82.

9. Thye-Rønn P, Sindrup SH, Arendt-Nielsen L, Brennum J, HotherNielsen O, Beck-Nielsen H: Effect of short-term hyperglycemia per se on nociceptive and non-nociceptive thresholds. Pain 1994, 56:43-49.

10. Holmen J, Midthjell K, Krüger $\varnothing$, Langhammer A, Holmen TL, Bratberg GH, Vatten L, Lund-Larsen PG: The Nord-Trøndelag Health Study 1995-1997 (HUNT 2): Objectives, contents methods and participation. Nor J Epidemiol 2003, 13:19-32.

II. Kuorinka I, Jonsson B, Kilbom A, Vinterberg H, Biering-Sørensen F, Andersson G, Jørgensen K: Standardised Nordic Questionnaires for the analysis of musculoskeletal symptoms. Appl Ergon 1987, 18:233-237.

12. Franzblau A, Salerno DF, Armstrong TJ, Werner RA: Test-retest reliability of an upper-extremity discomfort questionnaire in an industrial population. Scand J Work Environ Health 1997, 23:299-307.

13. Palmer K, Smith G, Kellingray S, Cooper C: Repeatability and validity of an upper limb and neck discomfort questionnaire: The utility of the Standardized Nordic Questionnaire. Occup Med 1999, 49: I7I-I75.

14. Næss S, Eriksen J, Midthjell K, Tambs K: Diabetes mellitus and psychological well-being. Change between 1984-1986 and 1995-1997. Results of the Nord-Trøndelag Health Study. J Diabetes Complications 2004, I 8(3): |4|-| 47.

15. Tishler M, Smorodin T, Vazina-Amit M, Ramot Y, Koffler M, Fishel B: Fibromyalgia in diabetes mellitus. Rheumatol Int 2003, 23:17I-173.

16. Wolak T, Weitzman S, Harman-Boehm I, Friger M, Sukenik S: Prevalence of fibromyalgia in type $\mathbf{2}$ diabetes mellitus. Harefuah 200I, 140:1006-1009.

17. Patucchi E, Fatati G, Puxeddu A, Coaccioli S: Prevalence of fibromyalgia in diabetes mellitus and obesity. Recenti Prog Med 2003, 94:163-165.

18. Carlsson S, Midthjell K, Tesfamarian MY, Grill V: Age, overweight and physical inactivity increase the risk of latent autoimmune diabetes in adults: results from the Nord-Trøndelag health study. Diabetologia 2007, 50:55-58.

19. Tantucci C, Bottini P, Fiorani C, Dottorini ML, Santeusanio F, Provinciali L, Sorbini CA, Casucci G: Cerebrovascular reactivity and hypercapnic respiratory drive in diabetic autonomic neuropathy. J Appl Physiol 200I, 90:889-896.

20. Wijnhoud AD, Koudstaal PJ, Dippel DW: Relationships of transcranial blood flow Doppler parameters with major vascular risk factors: TCD study in patients with a recent TIA or nondisabling ischemic stroke. J Clin Ultrasound 2006, 34:70-76.

21. Ziegler D: Treatment of diabetic polyneuropathy: update 2006. Ann N Y Acad Sci 2006, 1084:250-266.

22. Lee $\mathrm{JH}, \mathrm{McC}$ arty $\mathrm{R}$ : Pain threshold in diabetic rats: effects of good versus poor diabetic control. Pain 1992, 50:231-236.

23. Dyck PJ, Lambert EH, O'Brien PC: Pain in peripheral neuropathy related to rate and kind of fiber degeneration. Neurology 1976, 26:466-47I

24. Sharma AK, Duguid IG, Blanchard DS, Thomas PK: The effect of insulin treatment on myelinated nerve fibre maturation and integrity and on body growth in streptozotocin-diabetic rats. J Neurol Sci 1985, 67:285-97.

\section{Pre-publication history}

The pre-publication history for this paper can be accessed here:

http://www.biomedcentral.com/1471-2474/9/160/pre pub
Publish with Biomed Central and every scientist can read your work free of charge

"BioMed Central will be the most significant development for disseminating the results of biomedical research in our lifetime. "

Sir Paul Nurse, Cancer Research UK

Your research papers will be:

- available free of charge to the entire biomedical community

- peer reviewed and published immediately upon acceptance

- cited in PubMed and archived on PubMed Central

- yours - you keep the copyright

Submit your manuscript here:

http://www.biomedcentral.com/info/publishing_adv.asp
BioMedcentral 